The public should also be made aware of the dangers of the existing non-safety glass and of ways of making existing glass safe. This may be done by applying specifically produced and commercially available adhesive plastic sheets. The applications of such products costs little (about $£ 60$ in a three bedroomed semidetached house) and offers a very effective and safe alternative-and one that also protects against thieves attempting to gain entry. Some local authorities have used this sheeting to make their educational establishments safe. Before long it may become a legal requirement since one authority has been sued successfully when one of its tenants accidentally put his hand through a glass panel (Rimmer $v$ Liverpool Council; Public Relations Ltd, London, personal communication).

Road traffic accidents are seen by the community to be traumatic and expensive, and they receive a lot of attention by the press. The spotlight should be moved-at least some of the time-to accidents in the home and their prevention. The cost to the National Health Service of the treatment of glass injuries in England and Wales was estimated at about $£ 7.5 \mathrm{~m}$ in $1982 .{ }^{9}$ Yet these injuries are relatively easy to prevent.

\section{Kambiz Hashemi} Senior registrar

V Y SUBHEDAR Consultant

Accident and Emergency Department, Dudley Road Hospital, Birmingham B18 7QH

Correspondence to: Mr K Hashemi, Accident and Emergency Department, Mayday Hospital, Thornton Heath, Surrey CR4 7YE.

1 The Builder 1875

2 Hawkes N. Shattering peril of glass in the home. Observer 1978 Dec 17:3(cols 2-3).

Child Accident Prevention Trust. Architectural glass accidents to children. London: Child Accident Prevention Trust, 1982. (Paper No 3.)

Royal Society for the Prevention of Accidents. Subscriber briefing No 1. Glass safety. Birmingham: Royal Society for the Prevention of Accidents, 1983.

5 Morris M. Parliamentary oral question. House of Commons Official Repont (Hansard) 1980 July 18:988: cols $2033-7$

6 Jackson RH. Lacerations of glass in childhood. Br Med f 1981;283:1310-2.

7 Bell D. Two hundred glass injuries. Arch Dis Child 1984;59:672-3.

8 British Standards Institution. British standard code of practice for glazing of buildings (BS6262). London: British Standards Institution, 1982.

Ousby J, Wilson DH. 1086 consecutive injuries caused by glass. Injury 1982;13:427-30.

\section{Better health statistics}

Routine statistical data from the health service are sometimes inadequately exploited. In particular, opportunities for routine age and sex adjustment are not always taken, and little effort has been made to evolve reliable indices by which the public health may be assessed. A new publication from the Hospital In-Patient Enquiry (HIPE) of England (one in 10 random sample of hospital records) is a step in the right direction. The first Office of Population Censuses and Surveys Monitor-Trends 1979-1983 appeared in October 1985 and will appear with each annual HIPE summary table. These tabulations present trends over a five year period in the population rates of National Health Service discharges and deaths by age and sex, by classification of disease, and by surgical operation.

These same statistics appear in the much fuller annual HIPE tables, but the reader who wants trends over time has to work with several books and microfiches. The new publication gives at a glance all the unstandardised rates of discharge over five years. What we can learn is a function of $\underline{\underline{T}}$ what we know to be plausible determinants of particular $\bar{z}$ hospital discharge rates. Broadly, these come under four $\stackrel{\mathbb{Q}}{\varrho}$ headings: artefact of coding, supply of medical services, $c$ demand for hospital care, and morbidity. To take the last $\underline{\widehat{ }}$ first, if artefacts, supply, and demand did not influence changing discharge rates then these changes would have to be a reflection of changing morbidity. Then we would have what $m$ every epidemiologist seeks: temporal trends in population morbidity rates - which are the final outcome of the provision $\overrightarrow{\vec{S}}$ of health services.

In reality the interpretation of these trends is not as simple. The data do show, however, that discharge rates for indica- $\frac{\bar{\sigma}}{\bar{c}}$. tions for which admission to hospital is mandatory seem to $\vec{\nabla}$ have been constant over the five year period. At least in this

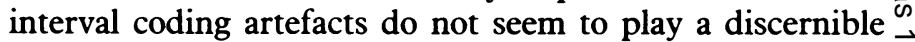
part in changing rates. Supply and demand must contribute, $?$ however, for several discharge types, and herein lies the real $\vec{\omega}$ problem of interpretation.

The first thing that strikes the eye is that almost all rates categorised by diagnostic group increased between 1979 and i 1983 - despite the exclusion of the expanding private sector. N Of the 200 or so categories, only 16 appeared to be I $^{2}$ decreasing. In aggregate, the discharge rate had increased by $N$ about $10 \%$ in the period. In other words, the number of $\frac{\omega}{\overrightarrow{0}}$ episodes of hospital admission per 1000 population was $10 \%$ higher than in 1979. That does not mean that people were $\stackrel{\circ}{\sigma}$ $10 \%$ more likely to be ill because reasons for referral change $>$ (demand), and reasons for admission change (supply), and perhaps some people get admitted more often.

So how can we sensibly use these data? Like most routine statistical publications their main utility lies in suggesting interesting epidemiological hypotheses. Sometimes such data may fairly conclusively refute a particular hypothesis, but this is rare. Simple accounts of hospital activity, including basic data such as age, sex, diagnosis, and operation, are $\stackrel{\odot}{\odot}$ worth while because they provide the basis for more specific $\underset{\vec{F}}{\vec{F}}$ investigation. There is no point in mounting large studies to $\frac{0}{3}$

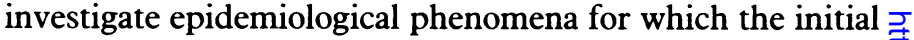
hypothesis was based on intuition or hunch when such ideas? cannot be validated or investigated even crudely from routine sources. Moreover, these tabulations can always be complemented with a local hospital activity analysis database, which is more detailed and presumably more useful because we tend to know more about the nature of local data.

For instance, both appendicitis and operations for it (as recorded) seem to be going down. Is this because the $\frac{}{2}$ population is aging or because the incidence is decreasing? $N$ Discharges for asthma are increasing quite appreciably. Is $\rightarrow$ this because of an increasing incidence or severity or a greater propensity to admit to hospital? Incision of the eardrum is $\mathbb{0}$ also increasing-presumably for insertions of grommets. స్ట And so on.... Such questions suggest the need for further ad $\bar{\sigma}$ hoc studies. The main problem with the interpretation of 6 these data, however, is that they are based on episodes and $\mathbb{D}$ not on persons, and until there is a clear yardstick with which $\stackrel{+}{+}$ to validate their quality, lingering doubts will inevitably remain. The new tables go some way towards that by facilitating the study of temporal trends.

University Lecturer in Medical Statistics,

Department of Community Medicine and

General Practice

Radcliffe Infirmary,

Oxford OX2 6HE 